\title{
A Qualitative Study to Characterize the Humanistic Burden of Kabuki Syndrome in the United States and Canada
}

\author{
Christina Theodore-Oklota $\cdot$ Deborah S. Hartman - Deborah L. Hoffman • \\ Hans T. Björnsson
}

Received: July 10, 2021 / Accepted: October 7, 2021 / Published online: November 29, 2021

(C) The Author(s) 2021

\section{ABSTRACT}

Introduction: Kabuki syndrome is a rare congenital condition characterized clinically by unique facial features, abnormalities in the skeleton, finger pad abnormalities, and developmental delays, as well as a range of other health issues. Existing research lacks information on the daily burden of living with Kabuki syndrome.

Methods: A survey collected caregiver- and patient-reported data about the experience of

C. Theodore-Oklota

Ultragenyx Pharmaceutical Inc., 5000 Marina

Boulevard, Brisbane, CA 94005, USA

e-mail: ctheodore-oklota@ultragenyx.com

D. S. Hartman · D. L. Hoffman ( $₫)$

Takeda Pharmaceuticals, 35 Landsdowne St,

Cambridge, MA 02139, USA

e-mail: Deborah.Hoffman@takeda.com

D. S. Hartman

e-mail: Deborah.Hartman@me.com

H. T. Björnsson

Johns Hopkins University, 733 N Broadway,

Baltimore, MD 21287, USA

e-mail: htb@hi.is

H. T. Björnsson

University of Iceland, Sturlugata 8, Reykjavik, Iceland

e-mail: hbjorns1@jhmi.edu

H. T. Björnsson

Landspitali University Hospital, Hringbraut,

Reykjavik, Iceland

e-mail: hanstb@landspitali.is living with Kabuki syndrome in order to better understand its presentation and effect on patients and their psychosocial well-being.

Results: A total of 68 participants ( $n=57$ caregivers and $n=11$ adolescents) were recruited from the USA and Canada. Caregiver survey participants reported developmental delays and lower IQ in individuals with Kabuki syndrome compared to the general population, as well as difficulty with cognitive-related tasks, need for educational accommodations, and difficulty with particular school subjects and with daily tasks. Additionally, participants reported significant emotional, social, and communicationrelated impacts of Kabuki syndrome. Adolescent data largely corroborated the information collected from caregivers, with the exception of adolescents reporting the emotional and social impacts as occurring less frequently.

Conclusions: Kabuki syndrome is a multidimensional disease which has substantial negative effects on physical, mental, emotional, and social aspects of health-related quality of life. This research adds to the limited existing body of literature on the clinical presentation of Kabuki syndrome and provides a novel perspective into the caregiver and adolescent perception of the burden of Kabuki syndrome.

Keywords: Kabuki syndrome; Survey; Caregivers; Adolescents; Patient burden; Humanistic burden; Patient research 


\section{Key Summary Points}

Kabuki syndrome is a rare genetic condition syndrome characterized by a range of signs and symptoms with an unmet need for treatment.

This manuscript details the results of an online survey conducted with 68 participants (57 caregivers of patients with Kabuki syndrome and 11 adolescents with Kabuki syndrome).

This work is a novel characterization of Kabuki syndrome from the caregiver and patient perspective.

This research was conducted with the intention of collecting patient- and observer-reported data on the burden of disease in Kabuki syndrome in order to help inform the Kabuki syndrome community as well as future clinical trial design.

\section{INTRODUCTION}

Kabuki syndrome, originally named "Kabuki make-up syndrome" or "Niikawa-Kuroki syndrome," is a rare multiple congenital anomaly syndrome characterized by a range of signs and symptoms [1]. Diagnosis is typically established by the presence of five characteristic manifestations: unique facial features, skeletal abnormalities, dermatoglyphic abnormalities, developmental delay, and short stature and/or genetic testing for mutations in the KMT2D or KDM6A genes [2-5]. The first Kabuki syndrome case was described in Japan in 1981 and the prevalence is thought to be one in every 32,000 live births, with 201 missense variants identified in a recent publication [6-10]. This condition is largely unknown by most primary care physicians and may be misdiagnosed, as the phenotype evolves over time and socio-emotional delays may be mistaken for other conditions $[3,9]$.

In addition to the cardinal features, a review of Kabuki syndrome descriptions in the literature found that patients may also experience system-wide issues, including feeding, neurological (e.g., seizures), cardiovascular, kidney, endocrine, ophthalmologic, hearing, dental, gastrointestinal, urinary tract, musculoskeletal, and immunologic issues [3, 4, 11, 12]. Individuals with Kabuki syndrome may also experience psychosocial issues, but are widely known to exhibit "pleasant and outgoing" behavior $[11,13]$.

Currently there are no effective treatments for Kabuki syndrome; the only treatment option is management of the manifestations of the condition [14]. This includes assistance with feeding (e.g., feeding tubes), antiepileptic medications for seizures, educational assistance, and various psychological interventions $[9,11,14]$. Kabuki syndrome is not typically associated with severe medical complications, and with proper management of congenital anomalies in childhood, prognosis for survival into adulthood is good [6].

Given the rarity of Kabuki syndrome and the lack of treatment research, there is a dearth of literature describing the signs, symptoms, and impacts experienced by patients and the overall burden of living with Kabuki syndrome. There are multiple benefits to collecting patient experience data in this area: it can provide information to parents and caregivers about what problems they may anticipate when they have a child with Kabuki syndrome; it gives information to healthcare providers about the overall condition so they have a broader understanding of the syndrome so they can address the multifaceted problems that occur in Kabuki syndrome; and it meets the needs of regulatory bodies that are increasingly looking for patient-centric data in their decision-making processes. For instance, patient experience data has been identified as a critical source for characterizing how a disease/condition affects a patient's everyday life and it plays a particularly important role in rare disease research as it may lead to a better understanding of diagnosis, 
disease-medical history, and management $[15,16]$.

The objective of this qualitative study was to obtain caregiver- and patient-reported data about the experience of living with Kabuki syndrome via an online survey in order to better understand its presentation and effect on patients. Survey research describing the clinical characteristics of Kabuki syndrome has been previously published, and this research specifically investigates the burden of living with Kabuki syndrome from the caregiver and patient perspective [17].

\section{METHODS}

\section{Recruitment and Eligibility Criteria}

Following ethics approval, the study was conducted in the USA and Canada. Ethics approval was obtained through Western Institutional Review Board (\#20172657). Caregivers were asked to provide consent for participation and parental permission for their adolescent's participation via an electronic informed consent form and adolescents were asked to provide consent for participation via an electronic assent form. Caregivers of adolescents with Kabuki syndrome were recruited through a clinical site (Johns Hopkins University), and Kabuki syndrome-specific advocacy groups (All Things Kabuki, Kabuki Syndrome Kids, and Kabuki Syndrome Network) via a recruitment flyer distributed through e-mail and social media. Caregivers were the primary target of the research because of the wide range of cognitive and intellectual deficits observed in patients with Kabuki syndrome, which could prevent them from successfully completing a lengthy survey. Interested participants reached out and were screened for eligibility via telephone; if eligible, they received a link to an electronic consent and online survey administered using the SurveyMonkey platform.

Eligibility criteria for caregivers of children or adults with Kabuki syndrome included verbal consent to be screened over the phone, at least 18 years old, located in the USA or Canada, able to identify how they learned about the survey, confirmation that they were able to read and complete an online survey in US English, and confirmation that they were willing and able to complete an online survey that took at least 45 min to complete. Caregivers also had to be able to identify when their son or daughter was diagnosed with Kabuki syndrome, and to confirm their son or daughter had at least one of the five cardinal manifestations of Kabuki syndrome: unique facial features, skeletal deformities, fingerprint abnormalities, mild or moderate intellectual disability, and/or growth deficiencies.

Additionally, for adolescents with Kabuki syndrome who were able and willing to complete a survey, their caregivers had to confirm the following eligibility criteria: adolescent was 12-17 years of age, inclusive, and able to complete an online survey either alone or with assistance from the caregiver.

\section{Data Collection}

Two online surveys were developed: (1) a caregiver-completed survey where respondents answered questions about their child's experience with Kabuki syndrome and (2) an adolescent-completed version. The caregiver survey was developed on the basis of a review of the existing literature as well as input from a clinical expert. The caregiver survey consisted of 156 questions presented to the participant using branched logic and included questions such as how they found out about the study as well as their child's diagnosis, age, gender, height, weight, living situation, education/employment status, cognitive and physical development, treatments, and overall burden of living with Kabuki syndrome. Select items from the caregiver survey were identified and modified to develop the adolescent survey. The adolescent survey consisted of a total of 32 questions and focused on the adolescent experience of living with Kabuki syndrome.

\section{Data Analysis}

All data was analyzed descriptively (e.g., frequency, mean, standard deviation, range, etc.) 
for all survey respondents and subgroups of interest (i.e., caregivers and adolescents). All open response items from the survey were analyzed using ATLAS.ti version 7.5.18 or higher (Atlas.ti $\mathrm{GmbH}$, Berlin), a software program designed specifically for qualitative data analysis. Specifically, codes were applied to specific text within each survey and then queried for frequency across surveys.

\section{RESULTS}

\section{Demographic and Health Characteristics}

A total of 68 participants $(n=57$ caregivers and $n=11$ adolescents) were recruited from the USA $(n=62,91.2 \%)$ and Canada $(n=6,8.8 \%)$. Most caregivers $(n=46,80.7 \%)$ learned about the survey through a Kabuki advocacy organization. Each caregiver cared for only one child with Kabuki syndrome. Caregivers had children with Kabuki syndrome ranging from 6 months to 32 years old, with an average age of 9 years (range 6 months-32 years). All caregivers reported that their children exhibit unique facial features ( $n=57,100.0 \%)$, and many also reported that they exhibit some of the other characteristic manifestations of Kabuki syndrome (Fig. 1).

Eleven adolescents also completed the survey; caregivers reported that two adolescents were able to complete the survey on their own and nine required assistance from the caregiver. Most of these adolescents were male $(n=7$, $63.6 \%$ ) and on average 14 years of age (range 12-16). See Table 1 for additional demographic and health information reported by all caregivers.

\section{Humanistic Burden}

\section{Delayed Childhood Milestones}

Table 2 reports the age at which participants with Kabuki syndrome reached certain developmental milestones and lists the age at which each milestone is expected to be achieved in the average population (i.e., children with typical development). In children with Kabuki syndrome, a wider range of ages at which developmental milestones were reached was reported with a substantially higher upper limit than that seen in children with typical development.

\section{Education Locations and Preferences}

Caregivers with children older than 5 years of age $(n=32)$ reported that their children attend

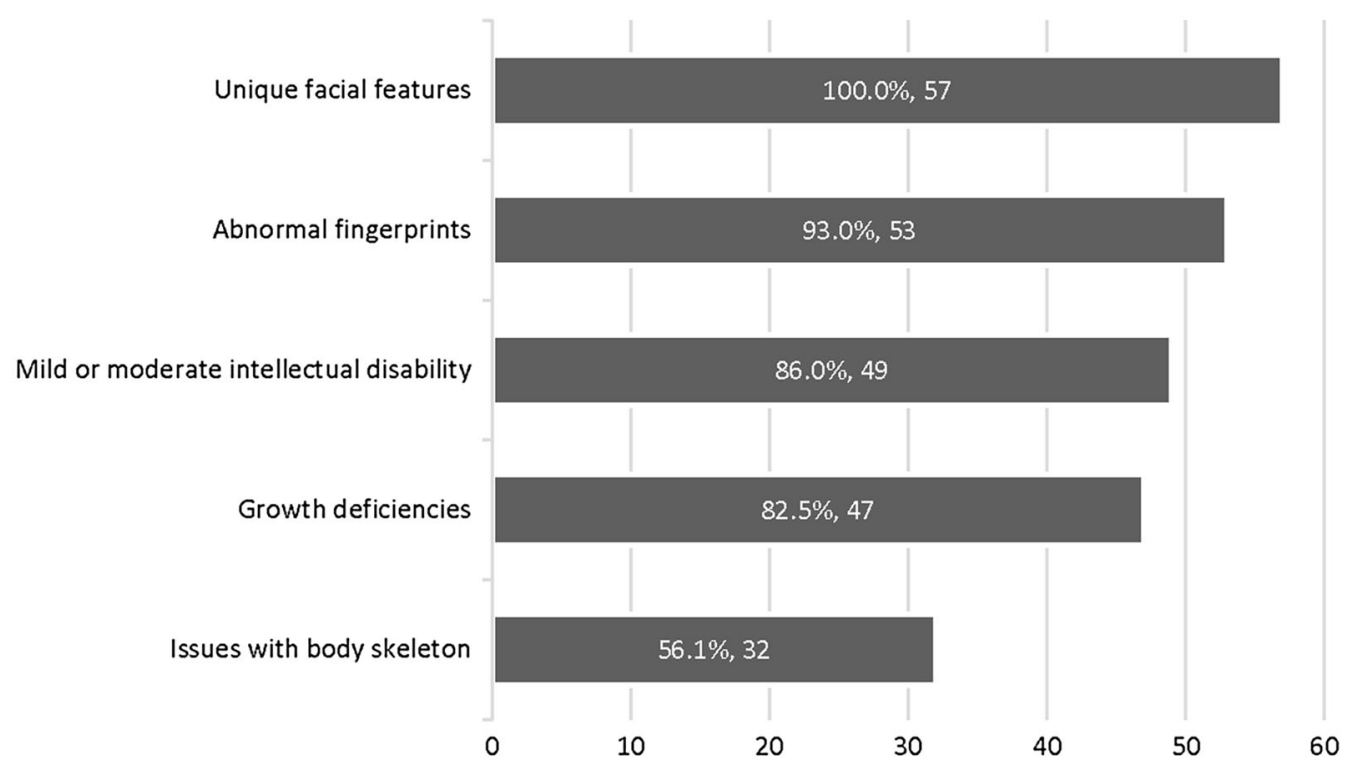

Fig. 1 Clinical manifestations of Kabuki syndrome $(n=57)$ 
Table 1 Caregiver-reported demographic and health information $(N=57)$

\begin{tabular}{|c|c|}
\hline Characteristic & $\begin{array}{l}\text { Characteristics of Kabuki } \\
\text { syndrome reported by } \\
\text { caregivers }(n=57)\end{array}$ \\
\hline \multicolumn{2}{|l|}{ Genetic testing } \\
\hline Received genetic testing & $54(94.7 \%)$ \\
\hline Mutation $K M T 2 D$ & $38(70.4 \%)$ \\
\hline Mutation $K D M 6 A$ & $6(11.1 \%)$ \\
\hline Don't know mutation & $3(5.6 \%)$ \\
\hline Other $^{a}$ & $7(13.0 \%)$ \\
\hline $\begin{array}{l}\text { Did not receive genetic } \\
\text { testing }\end{array}$ & $3(5.3 \%)$ \\
\hline \multicolumn{2}{|l|}{ Diagnosing clinician } \\
\hline Geneticist & $56(98.2 \%)$ \\
\hline Dysmorphologist & $1(1.8 \%)$ \\
\hline \multicolumn{2}{|c|}{$\begin{array}{l}\text { Person with Kabuki syndrome ages } 16 \text { and up work status } \\
(n=8)\end{array}$} \\
\hline Does not have a job & $7(87.5 \%)$ \\
\hline Has a job & $1(12.5 \%)$ \\
\hline \multicolumn{2}{|l|}{ Living situation } \\
\hline Lives at home & $56(98.2 \%)$ \\
\hline $\begin{array}{l}\text { Lives outside the home } \\
\text { (with assistance) }\end{array}$ & $1(1.8 \%)$ \\
\hline \multicolumn{2}{|l|}{ Education $^{\mathrm{b}}$} \\
\hline $\begin{array}{l}\text { Enrolled in special } \\
\text { education public school }\end{array}$ & $15(46.9 \%)$ \\
\hline $\begin{array}{l}\text { Enrolled in traditional } \\
\text { public school }\end{array}$ & $12(37.5 \%)$ \\
\hline
\end{tabular}

${ }^{a}$ Other responses were: clinically diagnosed $(n=2,3.7 \%)$, diagnosis made prior to gene identification $(n=1,1.9 \%)$, have not received results $(n=1,1.9 \%)$, and not positive for either mutation $(n=1,1.9 \%)$

${ }^{\mathrm{b}}$ Based on responses from caregivers with children older than 5 years $(n=32,56.1 \%)$

special education public schools $(n=15$, $46.9 \%)$, traditional public schools $(n=12$,
Table 2 Childhood development

\begin{tabular}{|c|c|c|c|}
\hline \multirow[t]{2}{*}{ Characteristic } & \multicolumn{2}{|c|}{$\begin{array}{l}\text { Age development } \\
\text { milestone achieved } \\
(\text { years })^{\mathbf{a}}\end{array}$} & \multirow{2}{*}{$\begin{array}{l}\text { Age } \\
\text { developmental } \\
\text { milestones are } \\
\text { achieved in } \\
\text { children with } \\
\text { typical } \\
\text { development } \\
\text { (years) [18, 19] } \\
\text { Range }\end{array}$} \\
\hline & $\begin{array}{l}\text { Average } \\
\text { (standard } \\
\text { deviation) }\end{array}$ & Range & \\
\hline Crawl & $1(0.8)$ & $0.5-3$ & $0.5-0.75$ \\
\hline $\begin{array}{l}\text { Develop fine } \\
\text { motor skills } \\
\text { (i.e., } \\
\text { grabbing/ } \\
\text { holding toys) }\end{array}$ & $1(1.5)$ & $0.4-7$ & $0.3-0.75$ \\
\hline $\begin{array}{l}\text { Engage in } \\
\text { reciprocal } \\
\text { play with } \\
\text { others }\end{array}$ & $4(3.2)$ & $0.8-15$ & $3-4$ \\
\hline Read & $7(2.0)$ & $4-13$ & $5-7$ \\
\hline $\begin{array}{l}\text { Sit without } \\
\text { assistance }\end{array}$ & $1(0.9)$ & $0.5-5$ & $0.5-0.75$ \\
\hline Speak & $2(1.3)$ & $0.4-5$ & $1-1.5$ \\
\hline Toilet train & $5(2.9)$ & $2-14$ & $1.5-3$ \\
\hline Walk $^{\mathrm{b}}$ & $2(1.1)$ & $0-7$ & $1-1.5$ \\
\hline
\end{tabular}

${ }^{a}$ Age range, average, and standard deviation were calculated on the basis of the total number of comprehensible answers reported by caregivers, and not the total number of respondents. The total number of participants reporting for each characteristic are as follows: crawl $(n=46)$; develop fine motor skills $(n=55)$; engage in reciprocal play with others $(\mathrm{n}=48)$; $\operatorname{read}(n=21)$; sit without assistance $(n=54)$; speak $(n=42)$; toilet train $(n=24)$; and walk $(n=44)$

${ }^{\mathrm{b}}$ One participant reported an age of zero for "walk," but did not specify the age in months

$37.5 \%)$, or special education private schools $(n=4,12.5 \%)$. Of the children who attend a traditional public or private school $(n=13)$, 
most were reported to have an individualized education plan $(n=12,92.3 \%)$ and seven (53.9\%) have a school aid.

Adolescents rated school subjects on a fivepoint scale of "very easy" to "very difficult." The subjects most commonly rated as "very difficult" were writing $(n=6,54.5 \%)$ and math $(n=4,36.4 \%)$. The only subjects rated as "very easy" were history $(n=2,18.2 \%)$ and reading $(n=2,18.2 \%)$. Further, nearly half of adolescents $(n=5,45.5 \%)$ said they prefer reading over math $(n=3,27.3 \%)$ or science $(n=2$, $18.2 \%)$.

\section{Difficulty with Daily Activities}

Caregivers and adolescents rated difficulty with certain daily tasks or activities, some related to motor skills. Caregivers most commonly rated the following tasks as "extremely difficult" for their child: washing hair $(n=24,42.1 \%)$, pronouncing words $(n=19,33.3 \%)$, and bathing $(n=18,31.6 \%)$. Other difficult tasks included brushing hair, brushing teeth, and getting dressed. Tasks most commonly rated as "not at all difficult" were facial non-verbal communication $(n=31,54.4 \%)$. Caregivers were asked separately about providers their child sees for their Kabuki syndrome, and reported seeing a physical therapist ( $n=45,78.9 \%)$, an occupational therapist $(n=42,73.7 \%)$, and a speech therapist ( $n=43,75.4 \%)$. See Fig. 2 for all caregiver ratings for all tasks.

Adolescents were asked to rate the difficulty of brushing their hair, brushing their teeth, dressing themselves, taking a bath, and washing their hair. The adolescent ratings were similar to caregiver ratings for bathing themselves $(n=4$, $36.4 \%$ said it was "very difficult"), washing hair ( $n=4,36.4 \%$ said it was "very difficult"). Unlike caregivers, adolescents often rated brushing their teeth as "not at all difficult" $(n=4,36.4 \%)$, brushing their hair as "not at all difficult" $(n=4$, $36.4 \%)$, and dressing themselves as "not at all difficult" ( $n=6,54.6 \%)$. Overall, adolescents generally rated tasks as less difficult than caregivers.

\section{Cognitive Impairment}

A little less than half of caregivers $(n=27$, $47.4 \%)$ reported that their child with Kabuki syndrome had received IQ testing. Children were on average 10 years old (range 2-30) during their most recent test. IQ scores ranged from 40 to 91 with an average score of 68 , although ten caregivers who reported that their child received IQ testing $(37.0 \%)$ did not know their IQ score. For reference, an IQ of $85-114$ is considered an average level of intellectually ability [20]. Over half of caregivers $(n=32$, $56.1 \%$ ) also reported that their child had seen a neurologist.

Caregivers selected areas of concern identified by their child's IQ testing. The most common areas of concern included difficulty in reproducing a drawing $(n=20,74.1 \%)$, poor reasoning ( $n=19,70.4 \%)$, and difficulty with spatial relations $(n=19,70.4 \%)$. Other areas of concern included problem solving $(n=17$, $63.0 \%)$, speech or language problems $(n=14$, $51.9 \%)$, listening comprehension $(n=12$, $44.4 \%)$, lack of vocabulary $(n=10,37.0 \%)$, and poor memory ( $n=9,33.3 \%$ ) (Fig. 3 ).

Over half of all caregivers reported that the following cognitive-related tasks were difficult for their child: reading a map $(n=38,66.7 \%)$, completing a paper maze $(n=37,64.9 \%)$, math problems ( $n=37,64.9 \%)$, and/or completing a jigsaw puzzle $(n=36,63.2 \%)$. Caregivers also indicated that their children struggle with directions, as they experience difficulty following directions to a location $(n=30,52.6 \%)$, remembering directions to a location $(n=27$, $47.4 \%)$, getting around their neighborhood $(n=28,49.1 \%)$, and getting around school $(n=17,29.8 \%)$. Twenty-four caregivers $(42.1 \%)$ reported that their child gets lost easily and all eight caregivers of a child over 16 years of age (100.0\%) reported that their child is unable to operate a vehicle. Other cognitive tasks related to interpersonal skills that caregivers reported difficulty with were remembering names that go with faces $(n=19,33.3 \%)$ and recognizing faces $(n=7,12.3 \%)$ (Fig. 4).

\section{Emotional State}

Adolescents and caregivers were asked how Kabuki syndrome affects their or their child's 


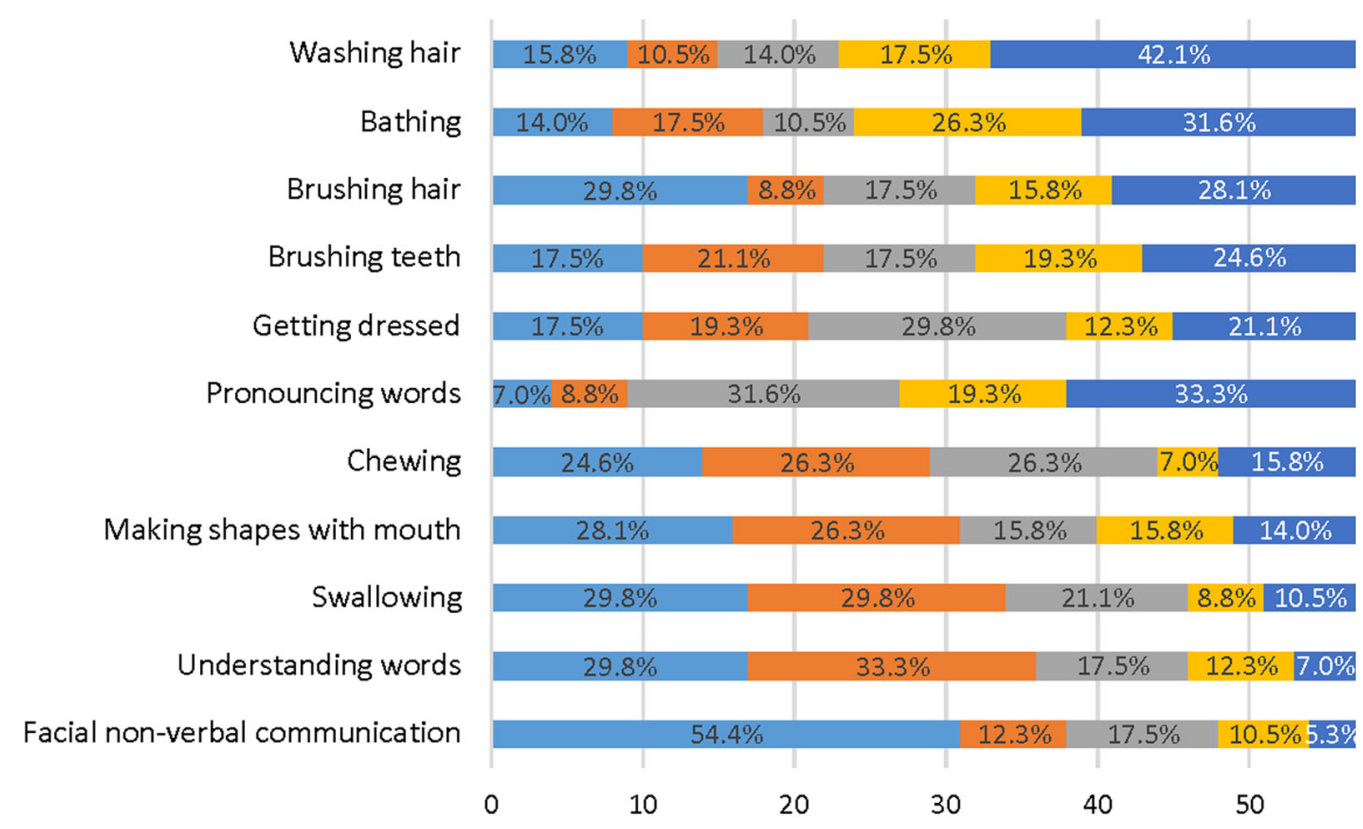

$\square$ Not at all difficult $\square$ A little difficult $\square$ Somewhat difficult $\square$ Very difficult $\square$ Extremely difficult

Fig. 2 Level of difficulty with certain daily tasks as rated by caregivers $(n=57)$

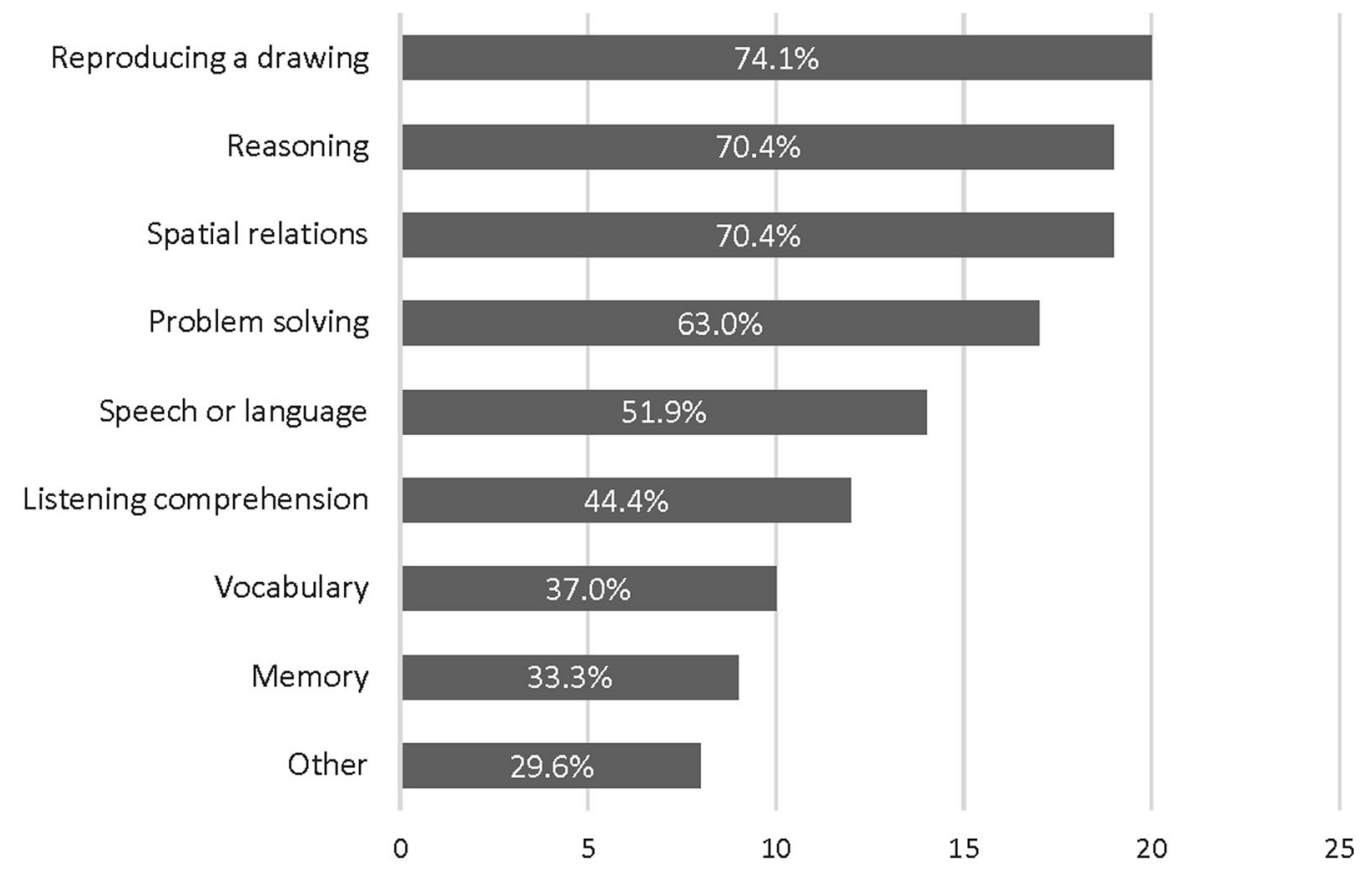

Fig. 3 Areas of concern identified by IQ testing as reported by caregivers $(n=27)$

emotional state. When asked to rate the frequency of certain emotional impacts on a scale of "never," "rarely," "occasionally," "most of the time," and "all of the time," 11 caregivers $(19.3 \%)$ reported that their child felt anxious or worried either "all of the time" or "most of the 


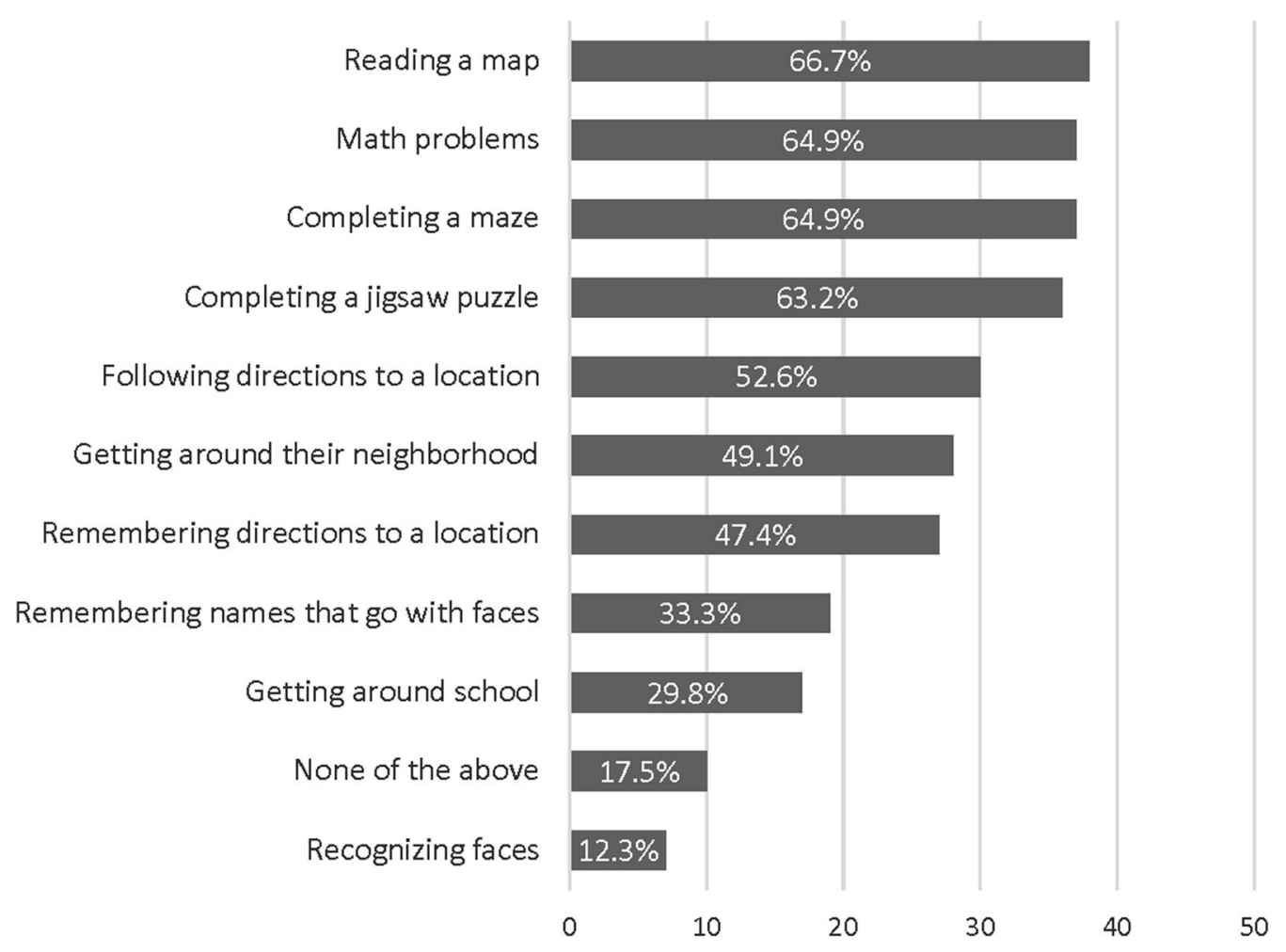

Fig. 4 Difficult cognitive tasks identified by caregivers $(n=57)$

time." Additionally, nine caregivers (15.8\%) reported that their child felt frustrated either "all of the time" or "most of the time." On the other hand, caregivers most commonly reported that their child "never" experienced the following: low self-esteem $(n=39,68.4 \%)$ and feeling self-conscious $(n=33,57.9 \%)$. Figure 5 depicts the frequencies of each emotional impact reported by caregivers. Some caregivers also reported that their child had seen a

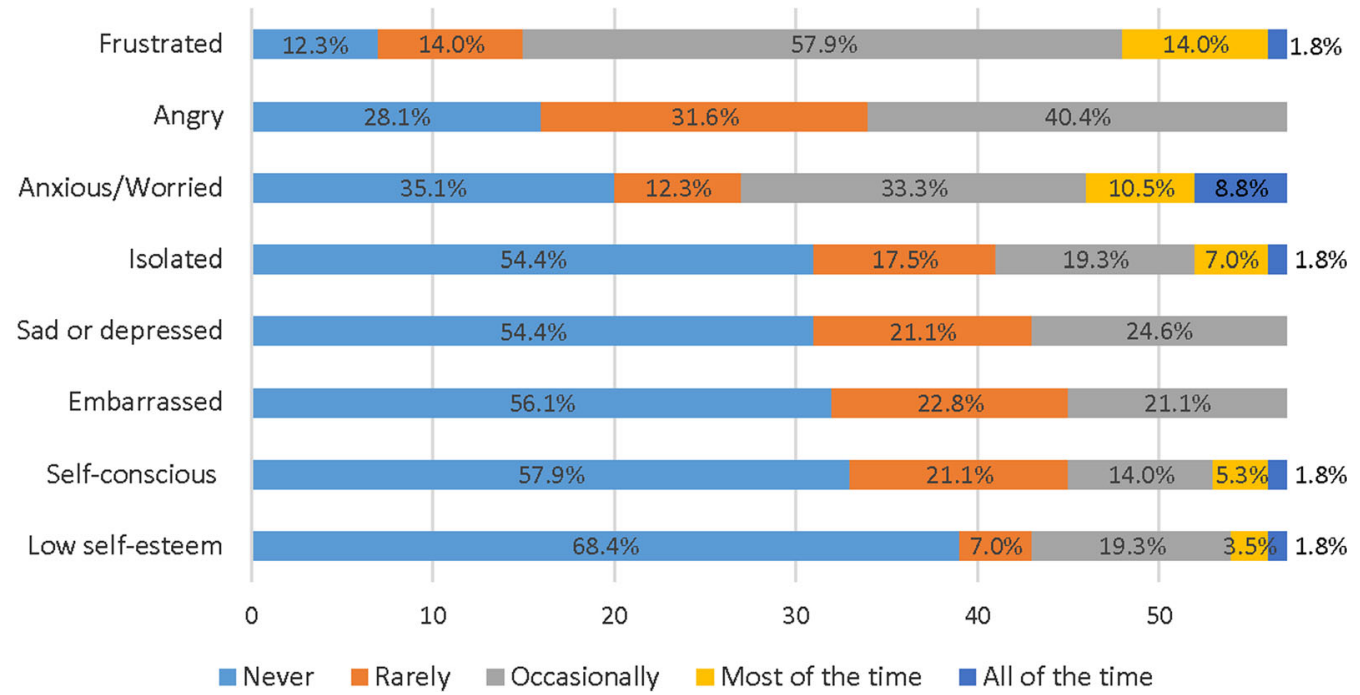

Fig. 5 Emotional impacts reported by caregivers $(n=57)$ 
psychologist $(n=9,15.8 \%)$ or a psychiatrist $(n=9,15.8 \%)$.

Adolescents endorsed the following statements as occurring "all of the time" or "most of the time": "I feel different from other people" $(n=5,45.5 \%)$, "I feel worried" $(n=3,27.3 \%)$, and "I feel frustrated" $(n=1,9.1 \%)$. On the other hand, adolescents most commonly reported that they "never" experience the following: "I feel alone" ( $n=6,54.6 \%)$, and "I feel nervous" ( $n=4,36.4 \%)$. Figure 6 depicts the frequencies of each emotional impact reported by adolescents.

\section{Impact on Social Life and Communication}

Some caregivers said their child avoided going out $(n=11,19.3 \%)$ and/or spending time with other people $(n=15,26.3 \%)$. Thirty-three caregivers $(57.9 \%)$ also reported that their child experienced "other" social impacts, including difficulty with the following: peer relationships ( $n=11,19.3 \%)$, making friends $(n=8,14.0 \%)$, communication ( $n=8,14.0 \%)$, social situations $(n=5,8.8 \%)$, playing $(n=7,12.3 \%)$, social boundaries $(n=3,5.3 \%)$, and receiving looks from people $(n=2,3.5 \%)$. Most caregivers ( $n=41,71.9 \%)$ said their child is able to communicate verbally.
Further, related to social impacts, adolescents reported the following as "never" occurring: avoiding hanging out with friends $(n=4$, $36.4 \%$ ), having difficulty showing people how they feel using facial expressions $(n=4,36.4 \%)$, having difficulty understanding words when someone is talking $(n=5,45.5 \%)$, having trouble taking or having conversations because of a stutter $(n=6,54.6 \%)$, and having trouble talking or having conversations because of slurred speech $(n=3,27.3 \%)$.

\section{Most Bothersome Aspect}

Adolescents were asked to report on the most bothersome or challenging aspect of living with Kabuki syndrome via an open response on the survey. Adolescents most commonly reported that the frequency of doctor visits (i.e., "having medical problems and going to the doctor all the time") was the most bothersome aspect of living with Kabuki syndrome $(n=3,27.3 \%)$. A wide range of unique responses were reported; one adolescent each (9.1\%) reported the following concepts as the most bothersome or challenging aspect: anxiety, difficulty hearing, difficulty with schoolwork, feeling different, feeling misunderstood, the need for many surgeries, unable to move quickly (i.e., "I can't move fast like other people"), and weekly

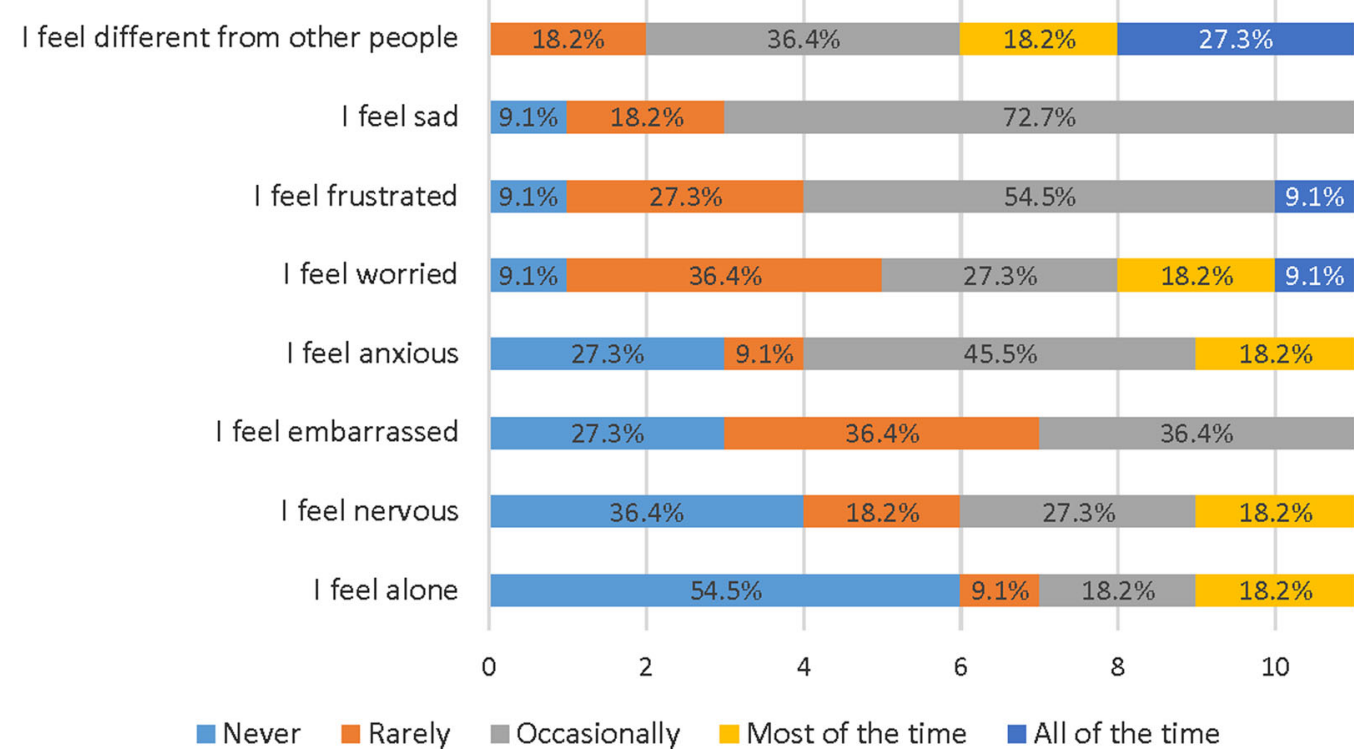

Fig. 6 Emotional impacts reported by adolescents $(n=11)$ 
immunoglobulin subcutaneous injections. Similarly, a range of unique responses were reported when adolescents were asked what they would like to improve; two adolescents $(18.2 \%)$ each said they would like to feel normal, have fewer surgeries, and/or improve their school work. One adolescent (9.1\%) each said they would like to improve their ability to play sports (i.e., "I would want to be able to shoot a basketball"), cure Kabuki syndrome, eliminate health problems (i.e., "take all my health problems away"), feel scared less often, improve their hearing, improve their immune system, make it easier to manage their Kabuki syndrome, and/or improve muscle strength.

\section{DISCUSSION}

The objective of this survey research was to collect data and information regarding the signs, symptoms, and associated impacts of Kabuki syndrome as experienced by patients. The characteristics associated with Kabuki syndrome are diverse and to date the authors are not aware of a comprehensive summary of all the physical, mental, and emotional effects those with Kabuki syndrome may experience.

Existing literature generally focuses on clinical characteristics and descriptions of patients, often from case studies in children $[1,4,6]$. While findings regarding the clinical manifestations of Kabuki syndrome are consistent with existing literature, this research took a more indepth look at the effect on day-to-day cognitive and personal tasks as well as social and emotional impacts. As a result of the difficulty in collecting data directly from patients with mild to moderate intellectual disability, this research is unique in that it collected the caregiver perception of patient burden. While it is typically preferable to measure health-related quality of life through self-report, when it is difficult to collect patient-level data a proxy report is often used and the caregiver's perception of their child's health status is what determines utilization of the healthcare system [21]. Finally, the adolescent data collected, while supplemental to the caregiver data, were unique in that they gave insight into the patient perspective of living with a physically and cognitively challenging condition during adolescence.

Overall, the results indicate that Kabuki syndrome is a physically, mentally, emotionally, and socially impactful condition. Patients reported wide-ranging issues across the topics covered in the survey, including developmental delays, lower IQ, difficulty in school, and difficulty with daily tasks, in addition to a range of psychosocial impacts. Data collected in this study appears to be in line with neurobehavioral features seen in other research [13]. The collection of caregiver-reported data and corresponding questions asked of adolescents paint a picture of a burdensome condition that requires multiple surgeries, various treatments which are only partially effective, and life-altering adaptations. Interestingly, there were both similarities and differences in the way caregivers and adolescents described the patient experience. For example, caregivers and adolescents rated difficulty with certain daily tasks relatively similarly, but adolescents were much less likely to rate emotional and social impacts as occurring as frequently as caregivers.

Of note, the results related to emotional and social aspects were not particularly striking and no social or emotional impacts (with the exception of anxiety) were named as the most bothersome aspects of living with Kabuki syndrome by adolescents. Additional research is warranted to gain more insight into the experience of both adolescent and adult patients, particularly to determine if the psychosocial state of patients with Kabuki syndrome is significantly worse than the general population. Future research could also include collection of caregivers' experiences caring for a child with Kabuki syndrome versus any other typical children they may have, as well as comparison of norm-based scores on formal assessments such as the SF-36 or EQ-5D to patients with Kabuki syndrome.

Despite the wide range of topics covered and the successful recruitment of caregivers and adolescents, this study had several limitations, mainly due to the nature of online survey administration. One such limitation was that there was no way to verify how much assistance an adult or adolescent had when completing 
their survey. While caregivers were asked to report if they administered the adolescent survey or their adolescent self-completed, it was impossible to verify the extent of assistance the adolescent received. Further, follow-up for clarification on responses was not possible when a participant's answer was unclear or seemed implausible. Face-to-face interviews would allow for better assessment of patients' cognitive abilities and opinions without assistance or input from a caregiver, thereby providing more robust and complete data on the symptoms and impacts of living with Kabuki syndrome. Another limitation was the fact that caregivers were asked to confirm diagnosis on behalf of their adolescent; no proof of medical diagnosis via clinician confirmation or medical records was required to participate. Given the method of recruitment through advocacy groups it is likely that all participants had Kabuki syndrome, but future research should require further confirmation of diagnosis to ensure they do not have a different genetic condition that could skew results.

The authors would like to note that in addition to the caregiver- and adolescent-reported data summarized here, three adults with Kabuki syndrome also completed a survey. While caregivers, adolescents, and adults were invited to participate, there was limited interest from the adult population. While the information provided by the adult population was supportive of the information collected from caregivers, the data were not included here because of the small sample size. Future studies recruiting adults with Kabuki syndrome who are able to participate should be prioritized.

\section{CONCLUSIONS}

This research is unique in that it captures patient and caregiver reports of the wide-ranging effects of living with Kabuki syndrome, from the perspective of those living in the USA and Canada; however, the authors acknowledge that further research is warranted including expansion to other countries and cultural backgrounds. This description of the humanistic burden of Kabuki syndrome complements the growing number of publications characterizing the genetic and clinical features of this disorder [4]. Importantly, new diagnostic criteria have just been published by an international consortium to ensure that it is possible to make the correct diagnosis of Kabuki syndrome, either with or without molecular genetic confirmation, to provide appropriate medical treatment and support the development of targeted therapies [22]. Given the lack of currently available patient- and caregiver-reported literature in this area, these results will help to raise the awareness both of the medical community to the needs of caregivers who have children with Kabuki syndrome and among caregivers to the experiences of others in their cohort. The Kabuki syndrome community is both well organized and enthusiastic about research participation and future studies will help further define patient reports of signs, symptoms, and impacts of Kabuki syndrome to help guide goals for potential future treatments.

\section{ACKNOWLEDGEMENTS}

We thank the participants of the study. Rene King, President \& Founder, All Things Kabuki Inc. was essential to participant recruitment and the overall success of this study.

Funding. No funding was received for this manuscript but Hans T. Björnsson is supported by a grant from the Louma G. Foundation. Hans T. Björnsson is also supported by grants from the Icelandic Research Fund (\#195835-051, \#206806-051) and the Icelandic Technology Development Fund (\#2010588-0611). Takeda Pharmaceutical Company funded the journal's Rapid Service and Open Access Fees.

Medical Writing Assistance. We thank Shayna Egan, Caitlin Pohl, and Christopher Evans from Endpoint Outcomes for writing assistance. Funding for writing assistance was received from Takeda Pharmaceutical Company. 
Authorship. All named authors meet the International Committee of Medical Journal Editors (ICMJE) criteria for authorship for this article, take responsibility for the integrity of the work as a whole, and have given their approval for this version to be published.

Authors' Contributions. Christina Theodore-Oklota, Deborah S. Hartman, Deborah L. Hoffman, and Hans T. Björnsson contributed to the conception and design of the work, drafted and revised the work, provided final approval of all versions, and agreed to be accountable for all aspects of the work.

Disclosures. Christina Theodore-Oklota is employed by Ultragenyx Pharmaceutical Inc. who funded this research. Deborah Hoffman and Deborah Hartman are or were employed by Takeda Pharmaceuticals at the time this research was conducted. Hans T. Björnsson was a consultant for Millennium Pharmaceuticals at the time of this study.

Compliance with Ethics Guidelines. Caregivers were asked to provide consent for participation and parental permission for their adolescent's participation via an electronic informed consent form and adolescents were asked to provide consent for participation via an electronic assent form.

Data Availability. Data pertaining to this research is available upon request.

Open Access. This article is licensed under a Creative Commons Attribution-NonCommercial 4.0 International License, which permits any non-commercial use, sharing, adaptation, distribution and reproduction in any medium or format, as long as you give appropriate credit to the original author(s) and the source, provide a link to the Creative Commons licence, and indicate if changes were made. The images or other third party material in this article are included in the article's Creative Commons licence, unless indicated otherwise in a credit line to the material. If material is not included in the article's Creative Commons licence and your intended use is not permitted by statutory regulation or exceeds the permitted use, you will need to obtain permission directly from the copyright holder. To view a copy of this licence, visit http://creativecommons.org/licenses/by$\mathrm{nc} / 4.0 /$.

\section{REFERENCES}

1. Niikawa N, Kuroki Y, Kajii T, et al. Kabuki make-up (Niikawa-Kuroki) syndrome: a study of 62 patients. Am J Med Genet. 1988;31(3):565-89. https://doi. org/10.1002/ajmg.1320310312.

2. Aref-Eshghi E, Schenkel LC, Lin H, et al. The defining DNA methylation signature of Kabuki syndrome enables functional assessment of genetic variants of unknown clinical significance. Epigenetics. 2017;12(11):923-33. https://doi.org/10. 1080/15592294.2017.1381807.

3. Cheon CK, Ko JM. Kabuki syndrome: clinical and molecular characteristics. Korean J Pediatr. 2015;58(9):317-24. https://doi.org/10.3345/kjp. 2015.58.9.317.

4. Lepri FR, Cocciadiferro D, Augello B, et al. Clinical and neurobehavioral features of three novel kabuki syndrome patients with mosaic KMT2D mutations and a review of literature. Int J Mol Sci. 2018. https://doi.org/10.3390/ijms19010082.

5. Liu S, Hong X, Shen C, et al. Kabuki syndrome: a Chinese case series and systematic review of the spectrum of mutations. BMC Med Genet. 2015. https://doi.org/10.1186/s12881-015-0171-4.

6. Adam MP, Hudgins L. Kabuki syndrome: a review. Clin Genet. 2005;67:209-19. https://doi.org/10. 1111/j.1399-0004.2004.00348.x.

7. Bögershausen $\mathrm{N}$, Gatinois $\mathrm{V}$, Riehmer $\mathrm{V}$, et al. Mutation update for kabuki syndrome genes KMT2D and KDM6A and further delineation of X-linked Kabuki syndrome subtype 2. Hum Mutat. 2016;37(9):847-64. https://doi.org/10.1002/humu. 23026.

8. Faundes V, Malone G, Newman WG, Banka S. A comparative analysis of KMT2D missense variants in Kabuki syndrome, cancers and the general population. J Hum Genet. 2019;64(2):161-70. https:// doi.org/10.1038/s10038-018-0536-6.

9. Kasdon BD, Fox JE. Kabuki syndrome: diagnostic and treatment considerations. Mental Health Fam Med. 2012;9(3):171-179. http://www.ncbi.nlm.nih. gov/pubmed/23997823. 
10. Matsumoto N, Niikawa N. Kabuki make-up syndrome: a review. Am J Med Genet. 2003;117C(1): 57-65. https://doi.org/10.1002/ajmg.c.10020.

11. Adam M, Dugan S, Hudgins L, Hannibal M. Kabuki syndrome. In: Management of genetic syndromes: third edition, 2010; pp 469-477. https://doi.org/10. 1002/9780470893159.ch32.

12. Dentici ML, Di Pede A, Lepri FR, et al. Kabuki syndrome: clinical and molecular diagnosis in the first year of life. Arch Dis Child. 2015;100(2):158-64. https://doi.org/10.1136/archdischild-2013-305858.

13. Caciolo C, Alfieri P, Piccini G, et al. Neurobehavioral features in individuals with Kabuki syndrome. Mol Genet Genomic Med. 2018;6(3):322-31. https://doi.org/10.1002/mgg3.348.

14. Lu J, Mo G, Ling Y, Ji L. A novel KMT2D mutation resulting in Kabuki syndrome: a case report. Mol Med Rep. 2016;14(4):3641-5. https://doi.org/10. 3892/mmr.2016.5683.

15. Food and Drug Administration. Patient-focused drug development: collecting comprehensive and representative input guidance for industry, Food and Drug Administration Staff, and Other Stakeholders. 2020. pp. 1-28. http://www.fda.gov/Drugs/ GuidanceComplianceRegulatoryInformation/ Guidances/default.htm.

16. US Food and Drug Administration (FDA). Guidance for industry: rare diseases: natural history studies for drug development. FDA Guidance, (March 2019).

https://www.fda.gov/Drugs/
GuidanceComplianceRegulatoryInformation/

Guidances/default.htm.

17. Theodore-Oklota C, Egan S, Paulich M, et al. Caregiver-reported clinical characteristics and the burden associated with Kabuki syndrome. Am J Med Genet A. 2020;182(7):1592-600. https://doi.org/10. 1002/ajmg.a.61584.

18. Centers for Disease Control and Prevention. Developmental milestones. 2018. https://www.cdc. gov/ncbddd/actearly/milestones/index.html. Accessed March 2020.

19. Dosman CF, Goulden KJ, Dosman CF, Evidencebased milestone ages as a framework for developmental surveillance. Pediatr Child Health. 2012;17(10):561-8.

20. Charman T, Pickles A, Simonoff E, Chandler S, Loucas T, Baird G. IQ in children with autism spectrum disorders: data from the Special Needs and Autism Project (SNAP). Psychol Med. 2011;41(3):619-27. https://doi.org/10.1017/ S0033291710000991.

21. Varni JW, Seid M, Kurtin PS. PedsQL TM 4.0: reliability and validity of the pediatric quality of life inventory $\mathrm{TM}$ version 4.0 generic core scales in healthy and patient populations. Medical Care Care. 2001;39(8):800-12.

22. Adam MP, Banka S, Bjornsson HT, et al. Kabuki syndrome: international consensus diagnostic criteria. J Med Genet. 2019;56(2):89-95. https://doi. org/10.1136/jmedgenet-2018-105625. 